\title{
24 种十字花科短命植物的扩散体特征与扩散对策
}

\section{刘晓风 谭敦炎}

(新疆农业大学林学院, 乌鲁木齐 830052)

摘 要 对准噶尔荒漠中 24 种十字花科短命植物的扩散体特征与扩散对策的观测结果表明 种间果实和种子的 形态各异, 角果开裂与否与其木质化程度有关。木质化程度较高的角果不开裂。其中长角果以果节为扩散单元自 体扩散。而短角果有两种扩散单元，以果实为扩散单元的无辅助扩散结构或具翅或绵毛，分别进行自体或风媒扩 散; 以果序的一段为扩散单元的果实具坚硬呈勾状的喙, 通过果序梗断裂或附在动物体表散布，兼具自体扩散和动 物体外传播的二重性。木质化程度较低的角果开裂，以种子为单元扩散。其中微尘状种子无辅助扩散结构，在果 皮开裂时产生的张力或风力的作用下散布 粘液种子以水媒为主, 兼具风媒和动物传播的特点 粘液和翅并存的种 子具有风媒和水媒扩散的二重性。果翅等辅助扩散结构有利于长距离散布 绵毛及种皮粘液使果实或种子与地表 能更好地粘附 木质化结构及种皮粘液还具有保水和保护作用。从扩散的时空特征看, 24 种植物在扩散持续时间 上有集中扩散和持续扩散两种方式,前者避免了种子干旱失水和被捕食, 属逃逸对策; 后者形成空气种子库逐批扩 散，属保护对策。从空间上，异果芥(Diptychocarpus strictus)果序上、下部果实的开裂方式与时间、种子形态完全不同， 导致其扩散时间与距离不同; 离子芥 (Chorispora tenella) 等类群果实不同部位的果节非同步脱落以及爪花芥 (Oreoloma sulfureum) 果实上、下部木质化程度及开裂方式不同，导致其果节或种子的扩散时间不同。以上这些特征对于它 们在荒漠环境中成功地扩散、定居, 抵御干旱、逃避捕食, 避免同胞种子间的竞争、保障物种延续并扩大种群等, 具 有重要的生态学意义。

关键词 扩散综合征 生态适应 十字花科 短命植物 准噶尔荒漠

\section{DIASPORE CHARACTERISTICS AND DISPERSAL STRATEGIES OF 24 EPHEMER- AL SPECIES OF BRASSICACEAE IN THE JUNGGAR DESERT OF CHINA}

\author{
LIU Xiao-Feng and TAN Dun-Yan ${ }^{*}$ \\ College of Forestry Sciences , Xinjiang Agricultural University , Urumqi 830052 , China
}

\begin{abstract}
Aims Members of Brassicaceae are one of the most important groups of ephemeral plants in the Junggar Basin and serve many ecological roles in the desert. However, studies on dispersal syndromes of Brassicaceae, especially the ephemerals, are rare. This study addresses the following questions :1) what are the dispersal unit and the dispersal mode of these species ,2) what are the spatio-temporal patterns of dispersal of these species and 3) how are these characters adaptive to the arid desert environment?
\end{abstract}

Methods The study was conducted on 24 ephemeral species of Brassicaceae from June to October 2005 and 2006. We observed and recorded 1) morphology of the fruits and seeds ,2) dehiscence mode of the fruit, type of dispersal unit and accessory structures and 3 ) dispersal mode and its duration in natural habitats.

Important findings The dehiscence mode of fruit depends on degree of lignification. There are three types of dispersal units of the species whose pods cannot dehisce. Species whose dispersal unit is the fruit node are autochorous. Species in which dispersal occurs by the whole fruit have silicula. Some do not have accessory structures to dispersal, and the dispersal mode is autochorous. Others have wings or hairs and disperse by wind. Species whose dispersal unit is a section of the infructescence also have silicula with a hard and hooklike beak that can attach to the coat of animals. Species with pods that dehisce easily only disperse by seeds. Their seeds have three types. One type is tiny without any accessory structures for dispersal , and seeds are dispersed by wind. Seeds in the second type have wings, and their modes of dispersal are diverse, but the main one is hydrochory. Seeds in the third type have wings and mucilage and are dispersed by anemochory and 
hydrochory. There are two types of dispersal patterns, depending on duration of dispersal. The first type is the short-term dispersal pattern in which all dispersal units on the plant are dispersed from the mother plant mainly in June and July. In the second type, dispersal units are shed from the mother plant from June to October or even the next spring. In this pattern , pods in the upper and lower positions of one infructescence differ in morphology, degree of lignification, kind of dispersal unit, dispersal time and dispersal mode.

Key words dispersal syndromes , ecological adaptation , Brassicaceae , ephemerals , Junggar Desert

植物的扩散是指植物以各种散布器官 (扩散 体, Diaspore)离开母体到达一个安全(适于萌发、生 长和繁殖)生境的过程 (Harper，1977），是植物更新 的关键阶段 (Van der Pijl，1982; Howe \& Smallwood， 1982)。扩散综合征 (Dispersal syndromes) 是指与扩散 单元不同散布机制相联系的植物果实或种子的形态 特征、化学特性和物候特点的综合特征，这些特征主 要取决于不同的传播媒介, 如风力、水力和动物 (Van der Pijl, 1982 ; Howe \& Westley, 1988 ; Predavec, 1997 ; Arbeláez \& Parrado-Rosseli , 2005)。种子扩散 是植物生活史中的重要阶段, 它影响着种子时空尺 度上的定居方式、种子密度、种子捕食率、病原体攻 击率、种子与母株的距离、种子到达的生境类型以及 建成的植株将与何种植物竞争, 从而影响种子和幼 苗的存活, 最终影响母株及后代植物的适合度和种 群结构（Sinha \& Davidar，1992；Schupp，1988， 1993)。目前国内外有关种子或果实扩散的研究主 要集中在散布方式、散布距离、散布式样和机制等方 面(Arbeláez \& Parrado-Rosseli , 2005 ; Wender et al. , 2005 ; 杨允菲和祝玲, 1995 ; 马绍宾和李德铢, 2002)。研究种子和果实的扩散特征对了解植物种 子库及其更新格局、物种的生态适应及其种群对策、 种群和群落的结构和动态、更新和演替都有重要意 义(Sinha \& Davidar , 1992 ; Arbeláez \& Parrado-Rosseli , 2005 ; 李宏俊和张知彬, 2000 ; 韩有志和王政权, 2002 ; 张玉波等，2005)。

十字花科是被子植物中的一个大科, 全世界约 有 3500 种，主要分布在地中海至中亚和北美西部， 许多属生长在干旱的沙漠或干燥而寒冷的高山地 区，且有较多的一年生短命植物 (吴征镒等，2003)。 我国有十字花科植物约 425 种, 大约 $50 \%$ 的种类分 布在新疆(安争夕和周桂玲, 1995)。在已报道的新 疆北部约 205 种早春短命植物中,十字花科植物约 占 31 种(毛祖美和张佃民，1994)。这些种类大多分 布在荒漠、沙漠和毗邻的草原带中, 是准噶尔盆地中 荒漠植物群落的重要组成部分, 研究其果实和种子 特征有助于理解其时空扩散及建植。

本文通过观测研究准噶尔荒漠中常见的 24 种
十字花科短命植物的扩散特性，重点弄清两个问题： 1)这些植物的果实和种子的形态特征与扩散对策对 荒漠环境的适应特点,2)扩散的时空特征及其对荒 漠环境的适应特点。并分析探讨了它们对准噶尔荒 漠生态环境的适应对策, 以期为进一步研究这类植 物的种子库特点和种子萌发策略积累重要的数据资 料, 同时为全面探讨短命植物这一特殊生态类型植 物的生活史对策和适应机制以及为准噶尔荒漠的生 态保育提供重要的理论依据。

\section{1 材料和方法}

\section{1 材料和观测地点}

观察材料为生长在新疆北部准噶尔荒漠中的 24 种十字花科短命植物 (含变种) (表 1 ), 实验观测 在自然生境和实验地同时进行。实验地设在新疆农 业大学实验农场, 位于准噶尔盆地南缘, 地理坐标为 $43^{\circ} 48^{\prime} \mathrm{N} 、 87^{\circ} 34^{\prime} \mathrm{E}$; 海拔 $833 \mathrm{~m}$, 与附近短命植物大量 生长的自然生境相距不到 $3 \mathrm{~km}$ 。该地属于典型的 荒漠气候，生境条件与 24 种短命植物的原生境基本 相似(姚红和谭敦炎,2005)。用于实验地观测的材 料于 2004 年 5 月底 $\sim 6$ 月初收集种子,同年 8 月 10 日采用撒播的方式在实验地播种, 整个生长过程模 拟自然条件, 不浇水、不施肥。供试材料的采集地点 及生境条件见表 1 。

\section{2 观测方法}

\subsection{1 果实及种子形态特征观测}

2005 年和 2006 年 6 月，于果熟期从各采集地点 或实验地收集 24 种植物的果实及种子, 分别观察其 颜色、附属物的有无、种皮粘液的有无及果实的开裂 情况, 同时随机选取 20 个果实和 20 粒种子, 测量果 实的大小、每个果实的种子数。另将种子置于 Sartorius-BS210S 型( Max $120 \mathrm{~g}$, 感量 $0.0001 \mathrm{~g}$ ) 电子天平 上称其千粒重。利用 Excel 软件对有关数据进行统 计处理。

\subsection{2 扩散单元、扩散方式及扩散时间观测}

2005 年和 2006 年 $6 \sim 10$ 月，在野外及实验地对 24 种植物的扩散单元、辅助扩散结构、扩散媒介、扩 散方式及扩散持续时间进行仔细的观察和记录。 
表 124 种十字花科短命植物的采集地点和观测条件

Table 1 Information on habitat and observation site of 24 ephemeral species of Brassicaceae

\begin{tabular}{|c|c|c|c|c|}
\hline $\begin{array}{l}\text { 种名 } \\
\text { Species }\end{array}$ & $\begin{array}{l}\text { 采集地 } \\
\text { Locality }\end{array}$ & $\begin{array}{c}\text { 生境 } \\
\text { Habitat }\end{array}$ & $\begin{array}{c}\text { 海拔 } \\
\text { Elevation } \\
(\mathrm{m})\end{array}$ & $\begin{array}{c}\text { 观测条件 } \\
\text { Observation } \\
\text { condition }\end{array}$ \\
\hline $\begin{array}{l}\text { 异果芥 } \\
\text { Diptychocarpus strictus }\end{array}$ & $\begin{array}{l}\text { 新疆奎屯市南郊 } \\
\text { South suburb of Kuytun city , Xinjiang }\end{array}$ & $\begin{array}{l}\text { 荒漠 } \\
\text { Desert }\end{array}$ & 300 & $\mathrm{NH}, \mathrm{F}$ \\
\hline $\begin{array}{l}\text { 卷果涩芥 } \\
\text { Malcolmia scorpioides }\end{array}$ & $\begin{array}{l}\text { 新疆阜康市北沙窝 } \\
\text { Beishawo of Fukan city, Xinjiang }\end{array}$ & $\begin{array}{l}\text { 半固定沙丘 } \\
\text { Semi-stationary dune }\end{array}$ & 442 & $\mathrm{NH}, \mathrm{F}$ \\
\hline $\begin{array}{l}\text { 甘新念珠芥 } \\
\text { Neotorularia korolkovii }\end{array}$ & $\begin{array}{l}\text { 新疆乌鲁木齐市西郊 } \\
\text { West suburb of Urumqi city , Xinjiang }\end{array}$ & $\begin{array}{l}\text { 荒漠 } \\
\text { Desert }\end{array}$ & 870 & $\mathrm{NH}, \mathrm{F}$ \\
\hline $\begin{array}{l}\text { 爪花芥 } \\
\text { Oreoloma sulfureum }\end{array}$ & $\begin{array}{l}\text { 新疆乌鲁木齐市南郊 } \\
\text { South suburb of Urumqi city , Xinjiang }\end{array}$ & $\begin{array}{l}\text { 土质荒漠 } \\
\text { Terrene desert }\end{array}$ & 870 & $\mathrm{NH}, \mathrm{F}$ \\
\hline $\begin{array}{l}\text { 对枝菜 } \\
\text { Cithareloma vernum }\end{array}$ & $\begin{array}{l}\text { 新疆阜康市北沙窝 } \\
\text { Beishawo of Fukan city, Xinjiang }\end{array}$ & $\begin{array}{l}\text { 固定及半固定沙丘 } \\
\text { Stationary and semi-stationary dune }\end{array}$ & 442 & $\mathrm{NH}$ \\
\hline $\begin{array}{l}\text { 离子芥 } \\
\text { Chorispora tenella }\end{array}$ & $\begin{array}{l}\text { 新疆乌鲁木齐市西郊 } \\
\text { West suburb of Urumqi city , Xinjiang }\end{array}$ & $\begin{array}{l}\text { 荒漠 } \\
\text { Desert }\end{array}$ & 870 & $\mathrm{NH}, \mathrm{F}$ \\
\hline $\begin{array}{l}\text { 西伯利亚离子芥 } \\
\text { C. sibirica }\end{array}$ & $\begin{array}{l}\text { 新疆奇台县奇台农场 } \\
\text { Qitai farm of Qitai county, Xinjiang }\end{array}$ & $\begin{array}{l}\text { 草原 } \\
\text { Steppe }\end{array}$ & 1800 & $\mathrm{NH}, \mathrm{F}$ \\
\hline $\begin{array}{l}\text { 涩芥 } \\
\text { Malcolmia africana }\end{array}$ & $\begin{array}{l}\text { 新疆乌鲁木齐市西郊 } \\
\text { West suburb of Urumqi city , Xinjiang }\end{array}$ & $\begin{array}{l}\text { 砾质荒漠 } \\
\text { Gravel desert }\end{array}$ & 870 & $\mathrm{NH}, \mathrm{F}$ \\
\hline $\begin{array}{l}\text { 小鼠耳芥 } \\
\text { Arabidopsis pumila }\end{array}$ & $\begin{array}{l}\text { 新疆乌鲁木齐市西郊 } \\
\text { West suburb of Urumqi city , Xinjiang }\end{array}$ & $\begin{array}{l}\text { 荒漠 } \\
\text { Desert }\end{array}$ & 870 & NH \\
\hline $\begin{array}{l}\text { 粗果庭荠 } \\
\text { Alyssum dasycarpum }\end{array}$ & $\begin{array}{l}\text { 新疆阜康市北沙窝 } \\
\text { Beishawo of Fukan city, Xinjiang }\end{array}$ & $\begin{array}{l}\text { 荒漠 } \\
\text { Desert }\end{array}$ & 442 & $\mathrm{NH}, \mathrm{F}$ \\
\hline $\begin{array}{l}\text { 荒漠庭荠 } \\
\text { A. desertorum }\end{array}$ & $\begin{array}{l}\text { 新疆乌鲁木齐市西郊 } \\
\text { West suburb of Urumqi city , Xinjiang }\end{array}$ & $\begin{array}{l}\text { 砾质荒漠 } \\
\text { Gravel desert }\end{array}$ & 870 & $\mathrm{NH}, \mathrm{F}$ \\
\hline $\begin{array}{l}\text { 条叶庭荠 } \\
\text { A. linifolium }\end{array}$ & $\begin{array}{l}\text { 新疆乌鲁木齐市西郊 } \\
\text { West suburb of Urumqi city , Xinjiang }\end{array}$ & $\begin{array}{l}\text { 砾质荒漠 } \\
\text { Gravel desert }\end{array}$ & 870 & $\mathrm{NH}, \mathrm{F}$ \\
\hline $\begin{array}{l}\text { 抱茎独行菜 } \\
\text { Lepidium perfoliatum }\end{array}$ & $\begin{array}{l}\text { 新疆乌鲁木齐市西郊 } \\
\text { West suburb of Urumqi city , Xinjiang }\end{array}$ & $\begin{array}{l}\text { 砾质荒漠 } \\
\text { Gravel desert }\end{array}$ & 870 & $\mathrm{NH}, \mathrm{F}$ \\
\hline $\begin{array}{l}\text { 独行菜 } \\
\text { L. apetalum }\end{array}$ & $\begin{array}{l}\text { 新疆乌鲁木齐市南郊 } \\
\text { South suburb of Urumqi city , Xinjiang }\end{array}$ & $\begin{array}{l}\text { 荒漠草原 } \\
\text { Desert steppe }\end{array}$ & 1160 & NH \\
\hline $\begin{array}{l}\text { 乌头荠 } \\
\text { Euclidium syricum }\end{array}$ & $\begin{array}{l}\text { 新疆乌鲁木齐市西郊 } \\
\text { West suburb of Urumqi city , Xinjiang }\end{array}$ & $\begin{array}{l}\text { 荒漠 } \\
\text { Desert }\end{array}$ & 870 & $\mathrm{NH}, \mathrm{F}$ \\
\hline $\begin{array}{l}\text { 小果菘蓝 } \\
\text { Isatis minima }\end{array}$ & $\begin{array}{l}\text { 新疆克拉玛依 } \\
\text { Kelamayi city , Xinjiang }\end{array}$ & $\begin{array}{l}\text { 荒漠 } \\
\text { Desert }\end{array}$ & 230 & $\mathrm{NH}, \mathrm{F}$ \\
\hline $\begin{array}{l}\text { 宽翅菘蓝 } \\
\text { I. violascens }\end{array}$ & $\begin{array}{l}\text { 新疆阜康市北沙窝 } \\
\text { Beishawo of Fukan city, Xinjiang }\end{array}$ & $\begin{array}{l}\text { 固定及半固定沙丘 } \\
\text { Stationary and semi-stationary dune }\end{array}$ & 442 & $\mathrm{NH}, \mathrm{F}$ \\
\hline $\begin{array}{l}\text { 垂果四棱荠 } \\
\text { Goldbachia pendula }\end{array}$ & $\begin{array}{l}\text { 新疆乌鲁木齐市西郊 } \\
\text { West suburb of Urumqi city , Xinjiang }\end{array}$ & $\begin{array}{l}\text { 荒漠 } \\
\text { Desert }\end{array}$ & 870 & NH \\
\hline $\begin{array}{l}\text { 棱果糖芥 } \\
\text { Erysimum siliculosum }\end{array}$ & $\begin{array}{l}\text { 新疆阜康市北沙窝 } \\
\text { Beishawo of Fukan city, Xinjiang }\end{array}$ & $\begin{array}{l}\text { 沙丘 } \\
\text { Sand dune }\end{array}$ & 442 & $\mathrm{NH}, \mathrm{F}$ \\
\hline $\begin{array}{l}\text { 厚壁荠 } \\
\text { Pachypterygium multicaule }\end{array}$ & $\begin{array}{l}\text { 新疆阜康市北沙窝 } \\
\text { Beishawo of Fukan city, Xinjiang }\end{array}$ & $\begin{array}{l}\text { 砾石荒漠 } \\
\text { Gravel desert }\end{array}$ & 442 & NH \\
\hline $\begin{array}{l}\text { 舟果荠 } \\
\text { Tauscheria lasiocarpa }\end{array}$ & $\begin{array}{l}\text { 新疆乌鲁木齐市西郊 } \\
\text { West suburb of Urumqi city , Xinjiang }\end{array}$ & $\begin{array}{l}\text { 荒漠 } \\
\text { Desert }\end{array}$ & 870 & NH \\
\hline $\begin{array}{l}\text { 光果舟果荠 } \\
T . \text { lasiocarpa var. gymnocarpa }\end{array}$ & $\begin{array}{l}\text { 新疆乌鲁木齐市西郊 } \\
\text { West suburb of Urumqi city , Xinjiang }\end{array}$ & $\begin{array}{l}\text { 荒漠 } \\
\text { Desert }\end{array}$ & 870 & NH \\
\hline $\begin{array}{l}\text { 绵果荠 } \\
\text { Lachnoloma lehmannii }\end{array}$ & $\begin{array}{l}\text { 新疆阜康市北沙窝 } \\
\text { Beishawo of Fukan city, Xinjiang }\end{array}$ & $\begin{array}{l}\text { 沙丘 } \\
\text { Sand dune }\end{array}$ & 442 & NH \\
\hline $\begin{array}{l}\text { 丝叶芥 } \\
\text { Leptaleum filifolium }\end{array}$ & $\begin{array}{l}\text { 新疆石河子市南郊 } \\
\text { South suburb of Shihezi city , Xinjiang }\end{array}$ & $\begin{array}{l}\text { 粘土荒漠 } \\
\text { Clay desert }\end{array}$ & 700 & $\mathrm{NH}$ \\
\hline
\end{tabular}

$\mathrm{NH}$ : 自然生境 Natural habitat $\mathrm{F}$ : 实验地 Field 


\section{2 结果与分析}

\section{1 果实和种子的形态特征}

\section{1 .1 果实形态与开裂情况}

24 种植物的果实形态和开裂情况见表 2 。

24 种植物的果实有长角果和短角果两种类型， 长角果大多呈线形或圆柱形，而短角果大多呈圆形、 椭圆形或卵形。果实开裂与否与其木质化程度有 关 木质化程度较高的长、短角果均不开裂 (短角果 不开裂的有两类:一类无辅助扩散结构，另一类具果 翅、绵毛及坚硬呈勾状的果喙等辅助扩散结构); 木 质化程度低的均开裂。还有一些种类果序上不同位 置果实的形态及木质化程度或果实的不同部位木质 化程度不同, 开裂方式也不一样。这些特征说明 24 种植物在果实形态、大小、木质化程度以及开裂方式 上各具特点。

\subsection{2 种子形态特征}

24 种植物的种子形态特征见表 2 。

24 种植物的种子均较小, 大多近黄色或褐色。 其中长角果不开裂种类的种子千粒重为 $0.41 \sim 0.44$ $\mathrm{g}$ 短角果不开裂的种类除鸟头荠 (Euclidium syricum) (千粒重约 $0.66 \mathrm{~g}$ ) 外，其余种类的千粒重为 $1.33 \sim$ $4.41 \mathrm{~g}$ 。果实开裂种类根据种子大小及附属物的有 无可分为 3 类 : 1) 种子呈微尘状 (Dust-like) ,千粒重 在 $0.05 \sim 0.21 \mathrm{~g}$ 之间，无任何辅助扩散结构 ; 2) 种 子千粒重在 $0.16 \sim 0.69 \mathrm{~g}$ 之间，种皮具粘液；3)种 皮粘液和种翅共存,千粒重在 $1.48 \sim 2.04 \mathrm{~g}$ 之间。 此外，爪花芥( Oreoloma sulfureum) 的种子无辅助扩散 结构，千粒重约 $0.45 \mathrm{~g}$; 异果芥 (Diptychocarpus strictus) 花序上、下部果实的种子形态不同，上部果种子 较大, 翅较宽, 粘液较多, 而下部果种子较小, 翅较 窄粘液也较少。这些特征说明观察种类中开裂果 实中的种子在大小和形态上存在着与其扩散有关的 特点,而不开裂果实中的种子在大小和形态上没有 显著的特点。

\section{2 扩散单元、辅助扩散结构、扩散方式和持续时} 间

24 种植物的扩散单元、辅助扩散结构、扩散媒 介、扩散方式和扩散时间见表 3 。

24 种植物中, 长角果不开裂种类的果实在种子 间缢缩处断裂, 以果节为扩散单元, 每果实可断裂成 $14 \sim 25$ 个果节, 每果节含 1 粒种子, 无辅助扩散结
构，自体扩散短角果不开裂种类大多以果实为扩散 单元, 每果实含 $1 \sim 2$ 粒种子, 其中无任何辅助扩散 结构的果实主要进行自体扩散，具翅或绵毛的果实 借风媒扩散，但鸟头荠果实的扩散具连种性 (Synaptospermy），成熟时短角果间的果序梗可自动断裂，以 果序的一段 (果实 + 果梗 + 部分花序梗) 为扩散单 元，既可进行自体扩散，又可通过其坚硬呈勾状的果 喙附在动物体表传播，因此兼具自体扩散和动物体外 传播的二重性。果实开裂种类以种子为扩散单元。 其中微尘状种子借果皮开裂时产生的张力或在风力 作用下散布，具粘液种子的成熟果实开裂后，种子在 风力和降水作用下落在母株附近的地面上或粘附在 母株及周围其它植株的叶片上以及母株周围其它具 勾刺等附属物的果实或种子(如石果鹤辛 (Lappula lipschitzii)的小坚果) 上, 落在地面上的种子可随地表 径流漂浮、扩散 地表干燥后粘附在土壤表面; 而粘附 在叶片或其它果实及种子上的种子，在风力和动物的 作用下随附着物一起扩散，因此该类种子具有以水媒 为主兼具风媒和动物传播的多种扩散方式 粘液和翅 共存的种子，具风媒和水媒扩散的二重性。

从扩散持续时间上看,主要有集中扩散和持续 扩散两种方式。集中扩散方式: 扩散单元离开母株 的时间主要集中在 6 月上旬 $~ 7$ 月上旬。如小鼠耳 芥 (Arabidopsis pumila) 和棱果糖芥 (Erysimum siliculosum) 的长角果及条叶庭荠 (Alyssum linifolium) 的短角 果,成熟后在很短的时间内开裂，以种子为单元很快 扩散到母株周围的土壤缝隙里; 而垂果四棱荠 (Goldbachia pendula)、绵果荠 (Lachnoloma lehmannii) 和宽翅菘蓝 (Isatis violascens) 等果实不开裂,成熟后 以果实为单元很快自母株扩散出去。持续扩散方 式:扩散单元离开母株的时间可从果实成熟起一直 持续到 10 月，少数种类甚至持续到翌年春季。这类 植物的果实木质化程度通常较高, 如涩芥 (Malcolmia africana)、鸟头荠和离子芥 (Chorispora tenella) 等。 而在异果芥和爪花芥中, 由于同一花序上、下部果实 和同一果实上、下部的开裂方式不同 花序上部开裂 果实的种子以及果实上部开裂部分的种子扩散出 去, 而其余果实留在母株上, 至冬季降雪时仍不开 裂。这些特征说明 : 24 种十字花科短命植物分别以 果节、单个果实、果序的一段和种子为扩散单元，不 同扩散单元的辅助扩散结构不同，扩散媒介及扩散 方式各不相同，扩散持续时间也有差异。 
表 224 种十字花科短命植物的果实类型、果实形态特征、果实开裂情况及种子的数量和质量特征

Table 2 Types, morphological characteristics of fruits, and dehiscence/indehiscence of fruits and characteristics of seeds in 24 ephemeral species of Brassicaceae

\begin{tabular}{|c|c|c|c|c|c|c|c|c|c|c|c|}
\hline \multirow{3}{*}{$\begin{array}{l}\text { 种名 } \\
\text { Species }\end{array}$} & \multirow{3}{*}{$\begin{array}{l}\text { 果实 } \\
\text { 类型 } \\
\text { Fruit } \\
\text { type }\end{array}$} & \multicolumn{4}{|c|}{$\begin{array}{c}\text { 果实形态特征 } \\
\text { Morphological characteristics of fruits } \\
\end{array}$} & \multirow{3}{*}{$\begin{array}{l}\text { 果实开裂与否 } \\
\text { Fruit dehiscence or } \\
\text { indehiscence }\end{array}$} & \multirow{3}{*}{$\begin{array}{c}\text { 种子数/果 } \\
\text { Seed } \\
\text { numbers } \\
\text { per fruit } \\
\text { (Mean } \pm \\
S E \text { ) }\end{array}$} & \multicolumn{4}{|c|}{$\begin{array}{c}\text { 种子形态特征 } \\
\text { Morphological characteristics of seeds } \\
\end{array}$} \\
\hline & & \multirow{2}{*}{$\begin{array}{l}\text { 颜色 } \\
\text { Color }\end{array}$} & \multicolumn{2}{|c|}{$\begin{array}{l}\text { 大小 Size }(\mathrm{cm}) \\
(\text { Mean } \pm S E)\end{array}$} & \multirow{2}{*}{$\begin{array}{l}\text { 毛的有无 } \\
\text { Trichome }\end{array}$} & & & \multirow{2}{*}{$\begin{array}{l}\text { 颜色 } \\
\text { Color }\end{array}$} & \multirow{2}{*}{$\begin{array}{l}\text { 形状 } \\
\text { Shape }\end{array}$} & \multirow{2}{*}{$\begin{array}{c}\text { 千粒重 }(\mathrm{g}) \\
\text { Weight of } \\
1000 \text { seeds } \\
\text { (Mean } \pm \\
S E \text { ) }\end{array}$} & \multirow{2}{*}{$\begin{array}{c}\text { 有无粘液 } \\
\text { Mucilage } \\
(\mathrm{M}) \text { or } \\
\operatorname{not}(\mathrm{N})\end{array}$} \\
\hline & & & $\begin{array}{c}\text { 长 } \\
\text { Length } \\
\end{array}$ & $\begin{array}{c}\text { 宽 } \\
\text { Width } \\
\end{array}$ & & & & & & & \\
\hline $\begin{array}{c}\text { 异果芥 } \begin{array}{c}\text { 上部花序 } \\
\text { Diptycho- Upper inflorescence }\end{array}\end{array}$ & $\begin{array}{l}\text { 长角果 } \\
\text { Siliqua }\end{array}$ & $\begin{array}{c}\text { 黄色 } \\
\text { Yellowish }\end{array}$ & $\begin{array}{l}5.85 \pm \\
0.60\end{array}$ & $\begin{array}{c}0.34 \pm \\
0.02\end{array}$ & $\begin{array}{l}\text { 几无毛 } \\
\text { Nearly glabrous }\end{array}$ & $\begin{array}{c}\text { 开裂 } \\
\text { Dehiscent }\end{array}$ & $31.48 \pm 3.95$ & $\begin{array}{l}\text { 淡褐色 } \\
\text { Pale brown }\end{array}$ & $\begin{array}{c}\text { 近圆形 } \\
\text { Suborbicular }\end{array}$ & $2.04 \pm 0.06$ & $\begin{array}{l}\text { 有 } \\
\mathrm{M}\end{array}$ \\
\hline \begin{tabular}{lc}
\cline { 2 - 2 } $\begin{array}{l}\text { carpus } \\
\text { strictus }\end{array}$ & 下部花序 \\
& Lower inflorescence \\
\end{tabular} & $\begin{array}{l}\text { 长角果 } \\
\text { Siliqua } \\
\end{array}$ & $\begin{array}{l}\text { 黄色 } \\
\text { Yellowish }\end{array}$ & $\begin{array}{r}4.32 \pm \\
0.89 \\
\end{array}$ & $\begin{array}{c}0.30 \pm \\
0.04 \\
\end{array}$ & $\begin{array}{c}\text { 几无毛 } \\
\text { Nearly glabrous } \\
\end{array}$ & $\begin{array}{c}\text { 不开裂 } \\
\text { Indehiscent }\end{array}$ & $12.86 \pm 2.19$ & $\begin{array}{c}\text { 淡褐色 } \\
\text { Pale brown }\end{array}$ & $\begin{array}{c}\text { 近圆形 } \\
\text { Suborbicular }\end{array}$ & $1.87 \pm 0.12$ & $\begin{array}{l}\text { 有 } \\
\mathrm{M}\end{array}$ \\
\hline $\begin{array}{c}\text { 卷果涩芥 } \\
\text { Malcolmia scorpioides }\end{array}$ & $\begin{array}{l}\text { 长角果 } \\
\text { Siliqua }\end{array}$ & $\begin{array}{c}\text { 浅褐色 } \\
\text { Light brown }\end{array}$ & $\begin{array}{l}3.03 \pm \\
0.51\end{array}$ & $\begin{array}{l}0.10 \pm \\
0.00\end{array}$ & $\begin{array}{c}\text { 疏生短分叉毛和单毛 } \\
\text { Sparsely covered with short } \\
\text { forked and simple trichome }\end{array}$ & $\begin{array}{c}\text { 开裂 } \\
\text { Dehiscent }\end{array}$ & $38.20 \pm 8.00$ & $\begin{array}{l}\text { 桔黄色 } \\
\text { Orange } \\
\text { yellow }\end{array}$ & $\begin{array}{l}\text { 长圆形 } \\
\text { Oblong }\end{array}$ & $0.07 \pm 0.01$ & $\begin{array}{l}\text { 无 } \\
N\end{array}$ \\
\hline $\begin{array}{c}\text { 甘新念珠芥 } \\
\text { Neotorularia korolkovii }\end{array}$ & $\begin{array}{l}\text { 长角果 } \\
\text { Siliqua }\end{array}$ & $\begin{array}{l}\text { 黄褐色 } \\
\text { Yellow } \\
\text { brown }\end{array}$ & $\begin{array}{c}3.59 \pm \\
0.38\end{array}$ & $\begin{array}{c}0.10 \pm \\
0.01\end{array}$ & $\begin{array}{c}\text { 密被分叉毛 } \\
\text { Densely covered with } \\
\text { forked trichome }\end{array}$ & $\begin{array}{c}\text { 开裂 } \\
\text { Dehiscent }\end{array}$ & $41.10 \pm 4.75$ & $\begin{array}{l}\text { 黄褐色 } \\
\text { Yellow-bro } \\
\text { wn }\end{array}$ & $\begin{array}{l}\text { 长圆形 } \\
\text { Oblong }\end{array}$ & $0.14 \pm 0.01$ & $\begin{array}{l}\text { 无 } \\
N\end{array}$ \\
\hline $\begin{array}{c}\text { 爪花芥 } \\
\text { Oreoloma sulfureum }\end{array}$ & $\begin{array}{l}\text { 长角果 } \\
\text { Siliqua }\end{array}$ & $\begin{array}{c}\text { 浅褐色 } \\
\text { Light brown }\end{array}$ & $\begin{array}{l}5.72 \pm \\
0.73\end{array}$ & $\begin{array}{c}0.20 \pm \\
0.01\end{array}$ & $\begin{array}{c}\text { 几无毛 } \\
\text { Nearly glabrous }\end{array}$ & $\begin{array}{c}\text { 果体上部约 } 2 / 3 \text { 开裂而 } \\
\text { 下部 } 1 / 3 \text { 不开裂 } \\
\text { From the apex to about } 2 / 3 \\
\text { of the siliqua dehiscent } \\
\text { while the rest indehiscent }\end{array}$ & $27.30 \pm 5.96$ & $\begin{array}{c}\text { 浅褐色 } \\
\text { Light brown }\end{array}$ & $\begin{array}{l}\text { 长圆形 } \\
\text { Oblong }\end{array}$ & $0.45 \pm 0.01$ & $\begin{array}{l}\text { 无 } \\
N\end{array}$ \\
\hline $\begin{array}{c}\text { 对枝菜 } \\
\text { Cithareloma vernum }\end{array}$ & $\begin{array}{l}\text { 长角果 } \\
\text { Siliqua }\end{array}$ & $\begin{array}{c}\text { 黄色 } \\
\text { Yellowish }\end{array}$ & $\begin{array}{c}4.74 \pm \\
0.48\end{array}$ & $\begin{array}{c}0.43 \pm \\
0.02\end{array}$ & $\begin{array}{c}\text { 密被分叉毛 } \\
\text { Densely covered with } \\
\text { forked trichome }\end{array}$ & $\begin{array}{c}\text { 开裂 } \\
\text { Dehiscent }\end{array}$ & $20.55 \pm 2.52$ & $\begin{array}{c}\text { 淡黄褐色 } \\
\text { Pale yellow } \\
\text { brown } \\
\end{array}$ & $\begin{array}{c}\text { 卵形, 扁平 } \\
\text { Ovate, } \\
\text { compressed }\end{array}$ & $1.48 \pm 0.05$ & $\begin{array}{l}\text { 有 } \\
\mathrm{M}\end{array}$ \\
\hline $\begin{array}{c}\text { 离子芥 } \\
\text { Chorispora tenella } \\
\end{array}$ & $\begin{array}{l}\text { 长角果 } \\
\text { Siliqua }\end{array}$ & $\begin{array}{c}\text { 黄色 } \\
\text { Yellowish } \\
\end{array}$ & $\begin{array}{c}2.74 \pm \\
0.30\end{array}$ & $\begin{array}{c}0.20 \pm \\
0.00\end{array}$ & $\begin{array}{c}\text { 无 } \\
\text { Glabrous }\end{array}$ & $\begin{array}{c}\text { 不开裂 } \\
\text { Indehiscent }\end{array}$ & $16.40 \pm 2.30$ & $\begin{array}{l}\text { 黄褐色 } \\
\text { Yellow } \\
\text { brown } \\
\end{array}$ & $\begin{array}{l}\text { 长圆形 } \\
\text { Oblong }\end{array}$ & $0.44 \pm 0.03$ & $\begin{array}{l}\text { 无 } \\
\mathrm{N}\end{array}$ \\
\hline $\begin{array}{c}\text { 西伯利亚离子芥 } \\
\text { C. sibirica }\end{array}$ & $\begin{array}{l}\text { 长角果 } \\
\text { Siliqua }\end{array}$ & $\begin{array}{c}\text { 黄色 } \\
\text { Yellowish }\end{array}$ & $\begin{array}{c}2.13 \pm \\
0.15\end{array}$ & $\begin{array}{c}0.20 \pm \\
0.00\end{array}$ & $\begin{array}{c}\text { 无 } \\
\text { Glabrous }\end{array}$ & $\begin{array}{c}\text { 不开裂 } \\
\text { Indehiscent }\end{array}$ & $23.00 \pm 2.29$ & $\begin{array}{l}\text { 黄褐色 } \\
\text { Yellow } \\
\text { brown }\end{array}$ & $\begin{array}{l}\text { 长圆形 } \\
\text { Oblong }\end{array}$ & $0.41 \pm 0.03$ & $\begin{array}{l}\text { 无 } \\
N\end{array}$ \\
\hline $\begin{array}{c}\text { 涩芥 } \\
\text { Malcolmia africana }\end{array}$ & $\begin{array}{l}\text { 长角果 } \\
\text { Siliqua }\end{array}$ & $\begin{array}{c}\text { 暗紫色 } \\
\text { Dark purple }\end{array}$ & $\begin{array}{l}5.25 \pm \\
1.07\end{array}$ & $\begin{array}{c}0.15 \pm \\
0.00\end{array}$ & $\begin{array}{c}\text { 密生短毛 } \\
\text { Densely covered with short } \\
\text { trichome }\end{array}$ & $\begin{array}{c}\text { 开裂 } \\
\text { Dehiscent }\end{array}$ & $67.85 \pm 9.14$ & $\begin{array}{c}\text { 浅棕色 } \\
\text { Light brown }\end{array}$ & $\begin{array}{l}\text { 长圆形 } \\
\text { Oblong }\end{array}$ & $0.21 \pm 0.01$ & $\begin{array}{l}\text { 无 } \\
N\end{array}$ \\
\hline $\begin{array}{c}\text { 小鼠耳芥 } \\
\text { Arabidopsis pumila }\end{array}$ & $\begin{array}{l}\text { 长角果 } \\
\text { Siliqua }\end{array}$ & $\begin{array}{l}\text { 褐色 } \\
\text { Brown }\end{array}$ & $\begin{array}{l}1.86 \pm \\
0.33\end{array}$ & $\begin{array}{c}0.08 \pm \\
0.00\end{array}$ & $\begin{array}{c}\text { 被短小星状毛 } \\
\text { Covered with short stellate } \\
\text { trichome }\end{array}$ & $\begin{array}{c}\text { 开裂 } \\
\text { Dehiscent }\end{array}$ & $27.50 \pm 4.67$ & $\begin{array}{l}\text { 桔黄色 } \\
\text { Orange- } \\
\text { yellow }\end{array}$ & $\begin{array}{c}\text { 卵状椭圆形 } \\
\text { Ovate elliptic }\end{array}$ & $0.05 \pm 0.01$ & $\begin{array}{l}\text { 无 } \\
N\end{array}$ \\
\hline $\begin{array}{c}\text { 粗果庭荠 } \\
\text { Alyssum dasycarpum }\end{array}$ & $\begin{array}{l}\text { 短角果 } \\
\text { Silicula }\end{array}$ & $\begin{array}{c}\text { 黄色 } \\
\text { Yellowish }\end{array}$ & $\begin{array}{c}0.26 \pm \\
0.03\end{array}$ & $\begin{array}{c}0.23 \pm \\
0.03\end{array}$ & $\begin{array}{c}\text { 疏被短毛 } \\
\text { Densely covered with short } \\
\text { trichome }\end{array}$ & $\begin{array}{c}\text { 开裂 } \\
\text { Dehiscent }\end{array}$ & $4.00 \pm 0.00$ & $\begin{array}{l}\text { 淡棕褐色 } \\
\text { Pale brown }\end{array}$ & $\begin{array}{l}\text { 卵形, 略压扁 } \\
\text { Ovate, slightly } \\
\text { compressed }\end{array}$ & $0.36 \pm 0.00$ & $\begin{array}{l}\text { 有 } \\
\mathrm{M}\end{array}$ \\
\hline
\end{tabular}




\begin{tabular}{|c|c|c|c|c|c|c|c|c|c|c|c|}
\hline $\begin{array}{c}\text { 荒漠庭荠 } \\
\text { A. desertorum } \\
\end{array}$ & $\begin{array}{l}\text { 短角果 } \\
\text { Silicula } \\
\end{array}$ & $\begin{array}{c}\text { 黄色 } \\
\text { Yellowish } \\
\end{array}$ & $\begin{array}{c}0.32 \pm \\
0.02 \\
\end{array}$ & $\begin{array}{c}0.32 \pm \\
0.02 \\
\end{array}$ & $\begin{array}{c}\text { 无 } \\
\text { Glabrous }\end{array}$ & $\begin{array}{c}\text { 开裂 } \\
\text { Dehiscent }\end{array}$ & $4.00 \pm 0.00$ & $\begin{array}{c}\text { 褐色 } \\
\text { Brown }\end{array}$ & $\begin{array}{c}\text { 卵形, 略压扁 } \\
\text { Ovate, slightly } \\
\text { compressed } \\
\end{array}$ & $0.55 \pm 0.01$ & $\begin{array}{l}\text { 有 } \\
\mathrm{M}\end{array}$ \\
\hline $\begin{array}{l}\text { 条叶庭荠 } \\
\text { A. linifolium }\end{array}$ & $\begin{array}{l}\text { 短角果 } \\
\text { Silicula }\end{array}$ & $\begin{array}{c}\text { 黄色 } \\
\text { Yellowish }\end{array}$ & $\begin{array}{c}0.59 \pm \\
0.07\end{array}$ & $\begin{array}{c}0.38 \pm \\
0.02\end{array}$ & $\begin{array}{c}\text { 无 } \\
\text { Glabrous }\end{array}$ & $\begin{array}{c}\text { 开裂 } \\
\text { Dehiscent }\end{array}$ & $8.77 \pm 1.07$ & $\begin{array}{c}\text { 黄色 } \\
\text { Yellowish }\end{array}$ & $\begin{array}{l}\text { 卵形, 扁平 } \\
\text { Ovate, } \\
\text { compressed }\end{array}$ & $0.24 \pm 0.00$ & $\begin{array}{l}\text { 有 } \\
\mathrm{M}\end{array}$ \\
\hline $\begin{array}{c}\text { 抱茎独行菜 } \\
\text { Lepidium perfoliatum }\end{array}$ & $\begin{array}{l}\text { 短角果 } \\
\text { Silicula }\end{array}$ & $\begin{array}{l}\text { 浅黄色 } \\
\text { Buff }\end{array}$ & $\begin{array}{c}0.38 \pm \\
0.02\end{array}$ & $\begin{array}{c}0.39 \pm \\
0.02\end{array}$ & $\begin{array}{c}\text { 无 } \\
\text { Glabrous }\end{array}$ & $\begin{array}{c}\text { 开裂 } \\
\text { Dehiscent }\end{array}$ & $2.00 \pm 0.00$ & $\begin{array}{l}\text { 褐色 } \\
\text { Brown }\end{array}$ & $\begin{array}{l}\text { 卵形 } \\
\text { Ovate }\end{array}$ & $0.69 \pm 0.01$ & $\begin{array}{l}\text { 有 } \\
\mathrm{M}\end{array}$ \\
\hline $\begin{array}{c}\text { 独行菜 } \\
\text { L. apetalum }\end{array}$ & $\begin{array}{l}\text { 短角果 } \\
\text { Silicula }\end{array}$ & $\begin{array}{l}\text { 浅黄色 } \\
\text { Buff }\end{array}$ & $\begin{array}{c}0.24 \pm \\
0.02\end{array}$ & $\begin{array}{c}0.19 \pm \\
0.01\end{array}$ & $\begin{array}{c}\text { 无 } \\
\text { Glabrous }\end{array}$ & $\begin{array}{c}\text { 开裂 } \\
\text { Dehiscent }\end{array}$ & $2.00 \pm 0.00$ & $\begin{array}{c}\text { 红褐色 } \\
\text { Reddish } \\
\text { brown }\end{array}$ & $\begin{array}{c}\text { 长圆形 } \\
\text { Ovate-oblong } \\
\end{array}$ & $0.16 \pm 0.01$ & $\begin{array}{l}\text { 有 } \\
\mathrm{M} \\
\end{array}$ \\
\hline $\begin{array}{c}\text { 鸟头荠 } \\
\text { Euclidium syricum }\end{array}$ & $\begin{array}{l}\text { 短角果 } \\
\text { Silicula }\end{array}$ & $\begin{array}{l}\text { 灰棕色 } \\
\text { Grey brown }\end{array}$ & $\begin{array}{c}0.31 \pm \\
0.02\end{array}$ & $\begin{array}{c}0.19 \pm \\
0.01\end{array}$ & $\begin{array}{c}\text { 被短二叉毛 } \\
\text { Covered with forked } \\
\text { trichome }\end{array}$ & $\begin{array}{c}\text { 不开裂 } \\
\text { Indehiscent }\end{array}$ & $2.00 \pm 0.00$ & $\begin{array}{l}\text { 棕色 } \\
\text { Brown }\end{array}$ & $\begin{array}{l}\text { 卵形 } \\
\text { Ovate }\end{array}$ & $0.66 \pm 0.04$ & $\begin{array}{l}\text { 无 } \\
N\end{array}$ \\
\hline $\begin{array}{c}\text { 小果菘蓝 } \\
\text { Isatis minima }\end{array}$ & $\begin{array}{l}\text { 短角果 } \\
\text { Silicula }\end{array}$ & $\begin{array}{c}\text { 浅棕色 } \\
\text { Light brown }\end{array}$ & $\begin{array}{c}1.13 \pm \\
0.09\end{array}$ & $\begin{array}{c}0.23 \pm \\
0.03\end{array}$ & $\begin{array}{c}\text { 无毛或被少量短柔毛及缘 } \\
\text { 毛 } \\
\text { Glabrous or puberulent }\end{array}$ & $\begin{array}{c}\text { 不开裂 } \\
\text { Indehiscent }\end{array}$ & $1.00 \pm 0.00$ & $\begin{array}{c}\text { 浅褐色 } \\
\text { Light brown }\end{array}$ & $\begin{array}{l}\text { 窄圆形 } \\
\text { Narrowly } \\
\text { oblong }\end{array}$ & $1.68 \pm 0.04$ & $\begin{array}{l}\text { 无 } \\
N\end{array}$ \\
\hline $\begin{array}{l}\text { 宽翅菘蓝 } \\
\text { I. violascens }\end{array}$ & $\begin{array}{l}\text { 短角果 } \\
\text { Silicula }\end{array}$ & $\begin{array}{c}\text { 深褐色 } \\
\text { Dark brown }\end{array}$ & $\begin{array}{c}1.22 \pm \\
0.07\end{array}$ & $\begin{array}{c}0.60 \pm \\
0.05\end{array}$ & $\begin{array}{c}\text { 密生短单毛 } \\
\text { Densely puberulent with } \\
\text { minute } \\
\end{array}$ & $\begin{array}{c}\text { 不开裂 } \\
\text { Indehiscent }\end{array}$ & $1.00 \pm 0.00$ & $\begin{array}{l}\text { 黄褐色 } \\
\text { Yellow } \\
\text { brown } \\
\end{array}$ & $\begin{array}{l}\text { 长圆形 } \\
\text { Oblong }\end{array}$ & $4.41 \pm 0.13$ & $\begin{array}{l}\text { 无 } \\
N\end{array}$ \\
\hline $\begin{array}{c}\text { 垂果四棱莽 } \\
\text { Goldbachia pendula }\end{array}$ & $\begin{array}{l}\text { 短角果 } \\
\text { Silicula }\end{array}$ & $\begin{array}{c}\text { 黄色 } \\
\text { Yellowish }\end{array}$ & $\begin{array}{c}0.76 \pm \\
0.04\end{array}$ & $\begin{array}{c}0.26 \pm \\
0.03\end{array}$ & $\begin{array}{c}\text { 无 } \\
\text { Glabrous }\end{array}$ & $\begin{array}{c}\text { 不开裂 } \\
\text { Indehiscent }\end{array}$ & $2.00 \pm 0.00$ & $\begin{array}{c}\text { 黄色 } \\
\text { Yellowish }\end{array}$ & $\begin{array}{c}\text { 短圆柱形 } \\
\text { Short cylindric }\end{array}$ & $2.81 \pm 0.05$ & $\begin{array}{l}\text { 无 } \\
N\end{array}$ \\
\hline $\begin{array}{c}\text { 棱果糖芥 } \\
\text { Erysimum siliculosum }\end{array}$ & $\begin{array}{l}\text { 长角果 } \\
\text { Siliqua }\end{array}$ & $\begin{array}{l}\text { 浅黄色 } \\
\text { Buff }\end{array}$ & $\begin{array}{l}1.74 \pm \\
0.22\end{array}$ & $\begin{array}{l}0.15 \pm \\
0.00\end{array}$ & $\begin{array}{c}\text { 被灰白色短丁字毛 } \\
\text { Covered with grey t-shaped } \\
\text { trichome }\end{array}$ & $\begin{array}{c}\text { 开裂 } \\
\text { Dehiscent }\end{array}$ & $34.25 \pm 6.24$ & $\begin{array}{c}\text { 棕红色 } \\
\text { Red brown }\end{array}$ & $\begin{array}{l}\text { 长圆形 } \\
\text { Oblong }\end{array}$ & $0.29 \pm 0.03$ & $\begin{array}{l}\text { 无 } \\
N\end{array}$ \\
\hline $\begin{array}{c}\text { 厚壁莽 } \\
\text { Pachypterygium multicaule }\end{array}$ & $\begin{array}{l}\text { 短角果 } \\
\text { Silicula }\end{array}$ & $\begin{array}{l}\text { 黄色 } \\
\text { Yellowish }\end{array}$ & $\begin{array}{c}0.38 \pm \\
0.02\end{array}$ & $\begin{array}{c}0.29 \pm \\
0.02\end{array}$ & $\begin{array}{c}\text { 无 } \\
\text { Glabrous }\end{array}$ & $\begin{array}{c}\text { 不开裂 } \\
\text { Indehiscent }\end{array}$ & $1.00 \pm 0.00$ & $\begin{array}{c}\text { 黄色 } \\
\text { Yellowish }\end{array}$ & $\begin{array}{l}\text { 窄长圆形 } \\
\text { Narrowly } \\
\text { oblong } \\
\end{array}$ & $0.29 \pm 0.01$ & $\begin{array}{l}\text { 无 } \\
N\end{array}$ \\
\hline $\begin{array}{c}\text { 舟果荠 } \\
\text { Tauscheria lasiocarpa }\end{array}$ & $\begin{array}{l}\text { 短角果 } \\
\text { Silicula }\end{array}$ & $\begin{array}{l}\text { 褐色 } \\
\text { Brown }\end{array}$ & $\begin{array}{c}0.35 \pm \\
0.03\end{array}$ & $\begin{array}{c}0.30 \pm \\
0.02\end{array}$ & $\begin{array}{c}\text { 密被极短的白毛 } \\
\text { Densely covered with white } \\
\text { short trichome }\end{array}$ & $\begin{array}{c}\text { 不开裂 } \\
\text { Indehiscent }\end{array}$ & $1.00 \pm 0.00$ & $\begin{array}{c}\text { 黄色 } \\
\text { Yellowish }\end{array}$ & $\begin{array}{l}\text { 长圆形 } \\
\text { Oblong }\end{array}$ & $1.33 \pm 0.03$ & $\begin{array}{l}\text { 无 } \\
N\end{array}$ \\
\hline $\begin{array}{l}\text { 光果舟果荠 } \\
\text { T. lasiocarpa var. } \\
\text { gymnocarpa }\end{array}$ & $\begin{array}{l}\text { 短角果 } \\
\text { Silicula }\end{array}$ & $\begin{array}{c}\text { 浅褐色 } \\
\text { Light brown }\end{array}$ & $\begin{array}{c}0.34 \pm \\
0.03\end{array}$ & $\begin{array}{c}0.33 \pm \\
0.02\end{array}$ & $\begin{array}{c}\text { 无 } \\
\text { Glabrous }\end{array}$ & $\begin{array}{c}\text { 不开裂 } \\
\text { Indehiscent }\end{array}$ & $1.00 \pm 0.00$ & $\begin{array}{c}\text { 黄色 } \\
\text { Yellowish }\end{array}$ & $\begin{array}{l}\text { 长圆形 } \\
\text { Oblong }\end{array}$ & $1.45 \pm 0.04$ & $\begin{array}{l}\text { 无 } \\
N\end{array}$ \\
\hline $\begin{array}{c}\text { 绵果荠 } \\
\text { Lachnoloma lehmannii }\end{array}$ & $\begin{array}{l}\text { 短角果 } \\
\text { Silicula }\end{array}$ & $\begin{array}{l}\text { 黄褐色 } \\
\text { Yellow } \\
\text { brown }\end{array}$ & $\begin{array}{l}1.11 \pm \\
0.06\end{array}$ & $\begin{array}{c}0.36 \pm \\
0.04\end{array}$ & $\begin{array}{c}\text { 被长柔毛 } \\
\text { Covered with white long } \\
\text { trichome }\end{array}$ & $\begin{array}{c}\text { 不开裂 } \\
\text { Indehiscent }\end{array}$ & $2.00 \pm 0.00$ & $\begin{array}{l}\text { 褐色 } \\
\text { Brown }\end{array}$ & $\begin{array}{l}\text { 卵状三角形 } \\
\text { Ovate } \\
\text { triangular } \\
\end{array}$ & $3.47 \pm 0.06$ & $\begin{array}{l}\text { 无 } \\
N\end{array}$ \\
\hline $\begin{array}{c}\text { 丝叶芥 } \\
\text { Leptaleum filifolium }\end{array}$ & $\begin{array}{l}\text { 长角果 } \\
\text { Siliqua }\end{array}$ & $\begin{array}{c}\text { 灰褐色 } \\
\text { Grey brown }\end{array}$ & $\begin{array}{c}2.17 \pm \\
0.32\end{array}$ & $\begin{array}{c}0.14 \pm \\
0.01\end{array}$ & $\begin{array}{c}\text { 几无毛 } \\
\text { Nearly glabrous }\end{array}$ & $\begin{array}{c}\text { 开裂 } \\
\text { Dehiscent }\end{array}$ & $52.40 \pm 9.64$ & $\begin{array}{l}\text { 黄棕色 } \\
\text { Yellow } \\
\text { brown } \\
\end{array}$ & $\begin{array}{l}\text { 长圆状卵形 } \\
\text { Oblong ovate }\end{array}$ & $0.08 \pm 0.02$ & $\begin{array}{l}\text { 无 } \\
N\end{array}$ \\
\hline
\end{tabular}


表 324 种十字花科短命植物的扩散单元和时间、辅助扩散结构与扩散媒介及方式

Table 3 Dispersal unit, accessory structures for dispersal, dispersal time, medium and mode in 24 ephemeral species of Brassicaceae

\begin{tabular}{|c|c|c|c|c|c|}
\hline $\begin{array}{l}\text { 扩散单元 } \\
\text { Dispersal unit }\end{array}$ & $\begin{array}{c}\text { 种名 } \\
\text { Species }\end{array}$ & $\begin{array}{c}\text { 辅助扩散结构 } \\
\text { Accessory structures for } \\
\text { dispersal }\end{array}$ & $\begin{array}{c}\text { 扩散媒介 } \\
\text { Dispersal medium }\end{array}$ & $\begin{array}{c}\text { 扩散方式 } \\
\text { Dispersal mode }\end{array}$ & $\begin{array}{l}\text { 扩散时间 } \\
\text { Dispersal time }\end{array}$ \\
\hline \multirow{8}{*}{$\begin{array}{l}\text { 种子 } \\
\text { Seed }\end{array}$} & $\begin{array}{l}\text { 小鼠耳芥(Arabidopsis pumila)、丝叶芥(Leptaleum } \\
\text { filifolium)、棱果糖芥(Erysimum siliculosum) }\end{array}$ & $\begin{array}{c}\text { 无 } \\
\text { None }\end{array}$ & $\begin{array}{c}\text { 无 } \\
\text { None }\end{array}$ & $\begin{array}{l}\text { 自体扩散 } \\
\text { Autochory }\end{array}$ & $\begin{array}{l}\text { 6月 7月 } \\
\text { June to July }\end{array}$ \\
\hline & 涩芥(Malcolmia africana) & $\begin{array}{c}\text { 无 } \\
\text { None }\end{array}$ & $\begin{array}{c}\text { 无 } \\
\text { None }\end{array}$ & $\begin{array}{l}\text { 自体扩散 } \\
\text { Autochory }\end{array}$ & $\begin{array}{l}\text { 8月 10月 } \\
\text { August to October }\end{array}$ \\
\hline & $\begin{array}{c}\text { 甘新念珠芥(Neotorularia korolkovii)、卷果涩芥 } \\
\text { (Malcolmia scorpioides) }\end{array}$ & $\begin{array}{l}\text { 无 } \\
\text { None }\end{array}$ & $\begin{array}{c}\text { 无 } \\
\text { None }\end{array}$ & $\begin{array}{l}\text { 自体扩散 } \\
\text { Autochory }\end{array}$ & $\begin{array}{c}\text { 6月上旬 } \sim 9 \text { 月 } \\
\text { Early June to September }\end{array}$ \\
\hline & 爪花芥(Oreoloma sulfureum) & $\begin{array}{c}\text { 无 } \\
\text { None }\end{array}$ & $\begin{array}{c}\text { 无 } \\
\text { None }\end{array}$ & $\begin{array}{l}\text { 自体扩散 } \\
\text { Autochory }\end{array}$ & $\begin{array}{l}\text { 8月～翌年春季 } \\
\text { August to the next spring }\end{array}$ \\
\hline & 荒漠庭莽(Alyssum desertorum)、粗果庭莽(A. dasycarpum) & $\begin{array}{c}\text { 粘液 } \\
\text { Mucilage }\end{array}$ & $\begin{array}{l}\text { 水力 } \\
\text { Water }\end{array}$ & $\begin{array}{l}\text { 水媒扩散, 风媒扩散, 动物体外传播 } \\
\text { Hydrochory, anemchory, endozoochory }\end{array}$ & $\begin{array}{l}\text { 7月 10月 } \\
\text { July to October }\end{array}$ \\
\hline & $\begin{array}{c}\text { 条叶庭荠(A. linifolium)、抱茎独行菜(Lepidium } \\
\text { perfoliatum)、独行菜(L. apetalum) }\end{array}$ & $\begin{array}{l}\text { 粘液 } \\
\text { Mucilage }\end{array}$ & $\begin{array}{l}\text { 水力 } \\
\text { Water }\end{array}$ & $\begin{array}{l}\text { 水媒扩散, 风媒扩散, 动物体外传播 } \\
\text { Hydrochory, anemchory, endozoochory }\end{array}$ & $\begin{array}{l}\text { 6月 7月 } \\
\text { June to July }\end{array}$ \\
\hline & 对枝菜(Cithareloma vernum) & $\begin{array}{c}\text { 种翅, 粘液 } \\
\text { Wing of seed, mucilage }\end{array}$ & $\begin{array}{l}\text { 风力, 水力 } \\
\text { Wind, water }\end{array}$ & $\begin{array}{l}\text { 风媒扩散, 水媒扩散 } \\
\text { Anemchory, hydrochory }\end{array}$ & $\begin{array}{l}\text { 6月〜 7月 } \\
\text { June to July }\end{array}$ \\
\hline & 异果芥(Diptychocarpus strictus) (上部果Upper fruit) & $\begin{array}{c}\text { 种翅, 粘液 } \\
\text { Wing of seed, mucilage }\end{array}$ & $\begin{array}{l}\text { 风力, 水力 } \\
\text { Wind, water }\end{array}$ & $\begin{array}{l}\text { 风媒扩散, 水媒扩散 } \\
\text { Anemchory, hydrochory }\end{array}$ & $\begin{array}{c}\text { 6月 9月 } \\
\text { June to September }\end{array}$ \\
\hline \multirow{4}{*}{$\begin{array}{l}\text { 果实 } \\
\text { Fruit }\end{array}$} & 垂果四棱莽(Goldbachia pendula) & $\begin{array}{l}\text { 木质化果实 } \\
\text { Lignified fruit }\end{array}$ & $\begin{array}{l}\text { 重力 } \\
\text { Gravity }\end{array}$ & $\begin{array}{l}\text { 自体扩散 } \\
\text { Autochory }\end{array}$ & $\begin{array}{l}\text { 6月〜7月 } \\
\text { June to July }\end{array}$ \\
\hline & $\begin{array}{c}\text { 宽翅菘蓝(Isatis violascens)、小果菘蓝(I. minima)、舟果 } \\
\text { 荠(Taucheria lasiocarpa)、光果舟果莽(T. lasiocarpa var. } \\
\text { gymnocarpa)、厚壁莽(Pachypterygium multicaule) }\end{array}$ & $\begin{array}{c}\text { 果翅 } \\
\text { Wing of the fruit }\end{array}$ & $\begin{array}{l}\text { 风力 } \\
\text { Wind }\end{array}$ & $\begin{array}{c}\text { 风媒扩散 } \\
\text { Anemchory }\end{array}$ & $\begin{array}{l}\text { 6月～7月 } \\
\text { June to July }\end{array}$ \\
\hline & 异果芥(Diptychocarpus strictus) (下部果Lower fruit) & $\begin{array}{l}\text { 木质化果实 } \\
\text { Lignified fruit }\end{array}$ & $\begin{array}{l}\text { 无 } \\
\text { None }\end{array}$ & $\begin{array}{l}\text { 自体扩散 } \\
\text { Autochory }\end{array}$ & $\begin{array}{c}\text { 8月～翌年春季 } \\
\text { August to the next spring }\end{array}$ \\
\hline & 绵果荠(Lachnoloma lehmannii) & $\begin{array}{c}\text { 绵毛 } \\
\text { Long trichome }\end{array}$ & $\begin{array}{l}\text { 风力 } \\
\text { Wind } \\
\end{array}$ & $\begin{array}{c}\text { 风媒扩散 } \\
\text { Anemchory }\end{array}$ & $\begin{array}{l}\text { 6月〜 7月 } \\
\text { June to July }\end{array}$ \\
\hline $\begin{array}{c}\text { 果序的一段 } \\
\text { A section of inflorescence }\end{array}$ & 鸟头荠(Euclidium syricum) & $\begin{array}{c}\text { 果㗒 } \\
\text { Beak of fruit }\end{array}$ & $\begin{array}{c}\text { 动物或无 } \\
\text { Animal or None }\end{array}$ & $\begin{array}{l}\text { 自体扩散, 动物体外传播 } \\
\text { Autochory, endozoochory }\end{array}$ & $\begin{array}{l}\text { 7月 10月 } \\
\text { July to October }\end{array}$ \\
\hline $\begin{array}{c}\text { 果节 } \\
\text { Fruit node }\end{array}$ & $\begin{array}{c}\text { 离子芥(Chorispora tenella)、西伯利亚离子芥(Chorispora } \\
\text { sibirica) }\end{array}$ & $\begin{array}{c}\text { 木质化结构 } \\
\text { Lignified structure }\end{array}$ & $\begin{array}{l}\text { 无 } \\
\text { None }\end{array}$ & $\begin{array}{l}\text { 自体扩散 } \\
\text { Autochory }\end{array}$ & $\begin{array}{l}\text { 7月～翌年春季 } \\
\text { July to the next spring }\end{array}$ \\
\hline
\end{tabular}




\section{3 讨 论}

所观察的 24 种十字花科短命植物在长期的演 化过程中, 已形成了与其荒漠环境相适应的多样化 的果实和种子形态特征、果实的开裂方式及扩散对 策。

3.1 果实与种子的形态特征、扩散方式及其对荒漠 环境的适应对策

果实或种子的扩散方式是由扩散媒介及与扩散 相关的果实和种子特征所决定的 (Sinha \& Davidar, 1992) 其中种子大小、果皮或果实结构及果实开裂 方式对扩散起决定作用(Wender et al .,2005)。根 据繁殖体传播媒介的不同，植物的扩散方式可分为 自体扩散 (Autochory)、风媒扩散(Anemchory)、水媒扩 散 (Hydrochory)、动物扩散 (Zoochory) ( Van der Pijl , 1982 ; Howe \& Smallwood, 1982 ; Arbeláez \& ParradoRosseli , 2005)。

24 种十字花科短命植物的果实及种子形态特 征、扩散方式都是与准噶尔荒漠环境相适应的。以 果实为扩散单元的植物, 果实木质化程度均较高, 不 易开裂，能有效地保护种子不受食种子动物的侵扰。 其中, 具果翅和绵毛等附属扩散结构的果实, 能借风 力和荒漠地表径流漂浮扩散, 绵毛吸水后还能将果 实固着在地表从而增大其定居和种子萌发的机会， 并保护种子不受蚂蚁的侵害 (Sheldon \& Burrows， 1973 ）, 具坚硬勾状果喙的果实有利于荒漠动物的传 播。以种子为扩散单元的植物, 微尘状种子在风力 作用下落入荒漠地表的裂缝中, 并很快被地表粉尘 所覆盖，从而避免了种子被蚂蚁捕食，这与 Spergularia diandra 的扩散方式相似, 是一种 逃逸” ( Escape)扩散对策 (Gutterman，2002) ;种皮具粘液物质 的种子能随荒漠地表径流漂浮、扩散，地表干燥后粘 附在土壤表面,阻止了被雨水或风力进一步扩散 (Huang \& Gutterman，1999) ,有利于种子定居, 同时 种子与沙土表面紧密结合还可使种子大粒化,从而 阻止蚂蚁和其它食种子动物采集种子 (Huang et $a l$ ，2000 僙振英等，2001）这与 Gutterman 和 ShemTov (1996)及 Gutterman (2002) 对以色列 Negev 荒漠 中具粘液种子的 Plantago coronops 所观察的扩散方 式相似 粘液与翅共存的种子在风力和荒漠地表径 流的作用下能扩散更远，其附属扩散结构对种子定 居及防御捕食十分有利。

3.2 果实或种子扩散的时空特征及其对荒漠环境 的适应对策
从扩散时间看 24 种植物中集中扩散的种子扩 散持续时间较短, 种子能很快地扩散到母株周围的 荒漠土壤缝隙里, 从而避免了干旱失水和动物的捕 食 持续扩散的种类果实木质化程度较高, 不开裂或 开裂较慢, 从而形成了空气种子库 (Aerial seed bank) 这是一种保护的 (Protected) 扩散对策 (Gutterman, 2002)。从空间特征看, 24 种植物中有的种类 (如异果芥)果序上、下部果实开裂方式与时间不同， 种子形态也明显不同，从而导致其扩散时间与距离 不同，使后代能分布在更广泛的空间，从而在时空上 避免了同胞种子的资源竞争, 增加了在新生境中扩 大种群的可能性; 有的种类 (如离子芥等) 果实上不 同部位的果节非同步脱落导致其扩散时间不同，从 而延长了扩散持续时间；还有的种类 (如爪花芥) 果 实上、下部木质化程度及开裂方式不同, 也导致种子 扩散时间的不同。Gutterman (1978) 研究指出, 荒漠 植物扩散对策不同的种子, 其萌发特性也不相同, 如 十字花科的 Neotorularia torulosa 能产生两种不同形 态的角果, 花序上部的角果呈黄色, 木质化程度低, 种子成熟后在夏季靠风力扩散, 萌发快, 而下部的角 果呈暗褐色, 木质化程度高, 种子成熟后直到冬季降 水后才扩散, 萌发慢。Erucaria microcarpa 角果基部 的种子冬季开始萌发, 而角果顶端被封闭的种子萌 发受到长时间抑制(Gutterman，2002）;Cakile 属植物 同一果实上有两种扩散单元, 果实上部大而轻, 易脱 落, 下部小而重, 不易脱落, 因此上部果在流水中适 合长距离扩散, 而下部果易留在母株周围, 其种子的 萌发时间和萌发条件也不同( Maune \& Payne， 1989)。菊科的 Dimorphotheca polyptera 和 D. sinuate 同一花序也产生两种不同类型的扩散单元, 其盘花 散布距离较远, 萌发率较高, 而缘花散布距离较近, 萌发率较低且延迟萌发 (Beneke et al .,1992)。但本 研究所观察的 24 种植物中, 在扩散上存在时空差异 的果实或种子, 种子萌发是否也存在差异? 这些种 类的果实或种子的扩散机制与其居群分布式样的相 关性如何? 它们在萌发特性上是如何与荒漠环境相 适应的? 这些问题还有待于进一步研究探讨。

\section{参 考 文 献}

An ZX (安争夕), Zhou GL (周桂玲) (1995). Brassicaceae. In: Mao ZM (毛祖美) ed. Flora Xinjiangensis (新疆植物志),

2 (2). Xinjiang Science \& Technology \& Hygiene Publishing House, Urumqi. (in Chinese)

Arbeláez MV, Parrado-Rosseli A (2005). Seed dispersal modes of the sandstone plateau vegetation of the Middle Caquetá River re- 
gion, Colombian Amazonia. Biotropica, 34, 64-72.

Beneke K, Von Teichman I, van Rooyen MW, Theron GK (1992) . Fruit polymorphism in ephemeral species of Namaqualand. I . Anatomical differences between polymorphic diaspores of two Dimorphotheca species. South African Journal of Botany, $58,448-455$.

Gutterman Y (1978). Germinability of seeds as a function of the maternal environments. Acta Horticulturae, 83, 49 - 55 .

Gutterman Y, Shem-Tov S (1996). Structure and function of mucilaginous seed coats of Plantago coronopus inhabiting the Negev Desert of Israel. Israel Journal of Plant Sciences, 44, 125 - 134. Gutterman Y (2002). Survival Strategies of Annual Desert Plants. Springer-Verlag, Berlin.

Han YZ (韩有志), Wang ZQ (王政权) (2002). Spatial pattern of manchurian ash seed dispersal in secondary hardwood forests. Acta Phytoecologica Sinica (植物生态学报), 26, 51-57. (in Chinese with English abstract)

Harper JL (1977) . Population Biology of Plants. Academic Press, New York.

Howe HF, Smallwood J (1982) . Ecology of seed dispersal. Annual Review of Ecology and Systematics, 13, $201-228$.

Howe HF, Westley LC (1988). Mechanics and ecology of mutualism. In: Howe HF, Westley LC eds. Ecological Relationships of Plants and Animals. Oxford University Press, Oxford.

Huang ZY, Gutterman Y (1999). Water absorption by mucilaginous achenes of Artemisia monosperma : floating and germination as affected by salt concentrations. Israel Journal of Plant Sciences, $47,27-34$.

Huang ZY, Gutterman Y, Hu ZH (2000). Structure and function of mucilaginous achenes of Artemisia monosperma inhabition the Negev Desert of Israel. Israel Journal of Plant Sciences, 48, $255-266$.

Huang ZY (黄振英), Gutterman Y, Hu ZH (胡正海), Zhang XS (张新时) (2001). Seed germ in Artemisia sphaerocephala. I. The structure and function of the mucilaginous achene. Acta Phytoecologica Sinica (植物生态学报), 25, 22-28. (in Chinese with English abstract)

Li HJ (李宏俊), Zhang ZB (张知涁) (2000). Relationship between animals and plant regeneration by seed. I . Object, methods and significance. Chinese Biodiversity (生物多样性), 8, 405 - 412. (in Chinese with English abstract)

Mao ZM (毛祖美), Zhang DM (张佃民)（1994）. The conspectus of ephemeral flora in Northern Xinjiang. Arid Zone Research (干旱区研究) , 11 (3) , 1-26. (in Chinese)

Ma SB (马绍宾), Li DZ (李德铢) (2002). Dispersal and evolu- tion in higher plants. I . Diaspores, their quantity and life span as well as dispersal mechanisms. Acta Botanica Yunnanica (云 南植物研究), 24, 569-582. (in Chinese with English abstract)

Maune PA, Payne AM (1989). Fruit and seed polymorphism and its relation to seedling growth in the genus Cakile. Canadian Journal of Botany, 67, 2743-2750.

Predavec M (1997). Seed removal by rodents, ants and birds in the Simpson Desert, central Australia. Journal of Arid Environments, $36,327-332$.

Schupp EW (1988) . Factors affecting post-dispersed seeds, and the dynamics of a lowland forest in Malaysia. Biotropica, 19, $326-$ 333.

Schupp EW (1993). Quantity, quality and the effectiveness of seed dispersal by animals. Vegetatio, 107/108, 15-29.

Sheldon JC, Burrows FM (1973) . The dispersal effectiveness of the achene-pappus units of selected Compositae in steady winds with convection. New Phytologist, 72, 665-675.

Sinha A, Davidar P (1992). Seed dispersal ecology of a wind dispersed rain forest tree in the western Ghats, India. Biotropica, 24, $519-526$.

Van der Pijl L (1982). Principles of Dispersal in Higher Plants 3rd edn. Springer-Verlag, Berlin.

Wender NJ, Polisetty CR, Donohue K (2005). Density-dependent processes influencing the evolutionary dynamics of dispersal: a functional analysis of seed dispersal in Arabidopsis thaliana (Brassicaceae) . American Journal of Botany, 92, 960 - 971 .

Wu ZY (吴征镒), Lu AM (路安民), Tang YC (汤彦承), Chen ZD (陈之端), Li DZ (李德铢) (2003). The Families and Genera of Angiosperms in China (中国被子植物科属综论). Science Press, Beijing. (in Chinese)

Yang YF (杨允菲), Zhu L (祝玲) (1995). Analysis on the mechanism of seed dispersal of Puccinellia chinampoensis on alkalized meadow in Songnen Plain of China. Acta Botanica Sinica (植物学报), 37, 222-230. (in Chinese with English abstract)

Yao H (姚红), Tan DY (谭敦炎) (2005). Size-dependent reproductive output and life-history strategies in four ephemeral species of Trigonelia. Acta Phytoecologica Sinica (植物生态学 报), 29, 954 -960. (in Chinese with English abstract)

Zhang YB (张玉波), Li JW (李景文), Zhang H (张昊), Zou DL (邹大林), Wu FP (武逢平), Cheng CL (程春龙), Li JQ (李俊清), Li SY (李帅英) (2005). Spatiotemporal patterns of seed dispersal in Populus euphratica. Acta Ecologica Sinica (生 态学报), 25, 1994 - 2000. (in Chinese with English abstract) 